\title{
On RFID Application in the Tracking and Tracing System of Agricultural Product Logistics
}

\author{
Weihua Gan, Yuwei Zhu, and Tingting Zhang \\ School of Mechanical and Electronical Engineering, East China Jiaotong University, \\ 330013, Nanchang, P. R. China, \\ ganweihua8421@yahoo.com.cn, zhuyuwei3113@163.com, \\ $z . t . t .0812 @ 163 . c o m$
}

\begin{abstract}
Nowadays the low quality of agricultural products has resulted in some accidents in China. People are waiting for the arrival of the safe and high quality agricultural products than before. This paper takes the agricultural products' safety as an example to analyze the RFID application. Firstly, this paper describes the characteristics of logistics activities about the agricultural products. Then it introduces RFID technique in tracking and tracing system. Next this paper discusses the RFID application along the agricultural product supply chain step by step. Finally, it presents the prospect of RFID technique in tracking and tracing system of agricultural products by a case study of 2008 Olympic Games in Beijing.
\end{abstract}

Keywords: Agricultural products, Radio Frequency Identification (RFID), Tracking and Tracing System (TTS).

\section{Introduction}

Owing the chemical abusing and environment worsening, the quality of agricultural products is becoming a hot topic in China during the recent decades.

Although developed countries have attached importance to the tracking and tracing system in agricultural product logistics since the mad cow disease appeared, some developing countries are just beginning to realize the importance of agricultural products logistics ${ }^{[1]}$. Chinese government has established some corresponding laws and regulations, such as The Special Provision about Strengthening Safety Supervision and Management on Foods proposed by the State Council, Law on Agricultural Product's Quality Safety of The People's Republic of China ${ }^{[2]}$. It can be seen that the research on tracking and tracing in agricultural product logistics has been a priority of the agenda.

\section{Agricultural Products' Safety}

\subsection{Concept of Agricultural Products' Safety}

Agricultural product refers to the primary product in agriculture, including vegetation, animal, microorganism, etc. Agricultural product safety is an important component of 
food sanitation quality, which means that the agricultural product must have no negative effects on human healthy directly or potentially. Safe agricultural product refers to the agricultural product should neither contain the elements which harm or threaten health nor acute or chronic diseases to consumers and their offspring ${ }^{[3]}$.

\subsection{Influencing Factors of Agricultural Products' Safety}

Generally there are four factors influencing agricultural products' safety, they are ${ }^{[4]}$ :

(1) Growing environment: soil, water and air are the top three significant factors for agricultural products in their growing environment.

(2) Production condition: some pesticides, fertilizers, etc. are applied inevitably during the production of agricultural products. The biggest threats to public health are those high-poisonous and high-persistent pesticides, which are prohibited or restricted.

(3) Pest factor: all kinds of agricultural plants would suffer from pests along the processing. Accordingly it would influence the quality and appearance of those plants themselves.

(4) Management factor: the management activities related to growth and production are the key factors for agricultural products' safety, too. Moreover, the service quality and efficiency of agricultural product logistics would influence safety.

\section{Agricultural Product Logistics}

\subsection{Definition of Agricultural Product Logistics}

It is defined agricultural product logistics is the economic activity from agricultural product producer to the consumers in order to satisfy customers' demands, including

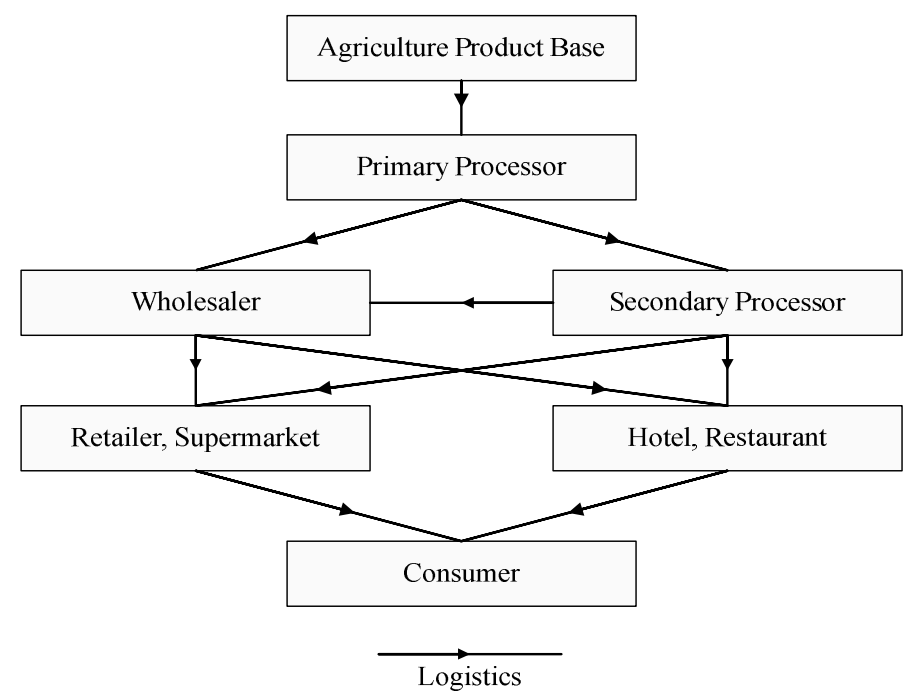

Fig. 1. Agricultural Product Logistics 
the links such as agricultural product production, purchasing, transportation, storage, loading and unloading, handling, package, processing, distribution and information processing ${ }^{[5]}$, it is shown in Figure 1.

\subsection{Characteristics and Classification of Agricultural Product Logistics}

Contrary to the industrial product, agricultural product has its own characteristics embodied in its life ${ }^{[6]}$ :

(1) Restricted by natural conditions, the growth of agricultural product is obviously seasonal, and the output is unstable. However, the requirement of agricultural product is lasting and stable.

(2) The planting regions are usually centralized within some areas, but the consumers are distributed all over the nation.

(3) Agricultural product almost grows depending on the nature, so it is not standardized.

(4) Agricultural product has short life cycle.

Owing to these characteristics, agricultural product logistics is different from industrial product logistics. Emphasis should be put on the package and processing of agricultural products.

According to the different classifying criterion, the categories of agricultural product logistics can be diversified. The classification of agricultural product logistics as shown in the Table 1:

Table 1. Classification of agricultural product logistics

\begin{tabular}{lll}
\hline No. & Criterion & Contents of categories \\
\hline 1 & logistics phase & production logistics, distribution logistics, waste logistics \\
2 & logistics object & $\begin{array}{l}\text { grain logistics, crops logistics, animals logistics, aquatic } \\
\text { products logistics, forest products logistics } \\
\text { producer-logistics-suppliers, buyer-logistics-suppliers, } \\
\text { third-party-logistics-suppliers }\end{array}$ \\
\hline
\end{tabular}

\section{Tracking and Tracing System of Agricultural Products}

\subsection{Definition of Tracking and Tracing System of Agricultural Products}

Tracking system refers to the ability of tracking the path of a particular unit or a batch of products from upstream to downstream along supply chain. Tracing system means the ability to distinguish the particular unit or a batch of products' source from downstream to upstream along supply chain ${ }^{[7]}$. In other words tracing is mainly used to discover quality problem. The process of tracking and tracing is shown in Figure 2:

Tracking and tracing system (TTS) of agricultural product logistics is an information management system linking each sector such as manufacture, inspection, supervision, consumption, etc. in order to display the health and safety-from farm to table. In addition, it helps establishing agricultural product safety information database, once food accidents occur, effective measures can be taken to control and recall along the food supply chain. 


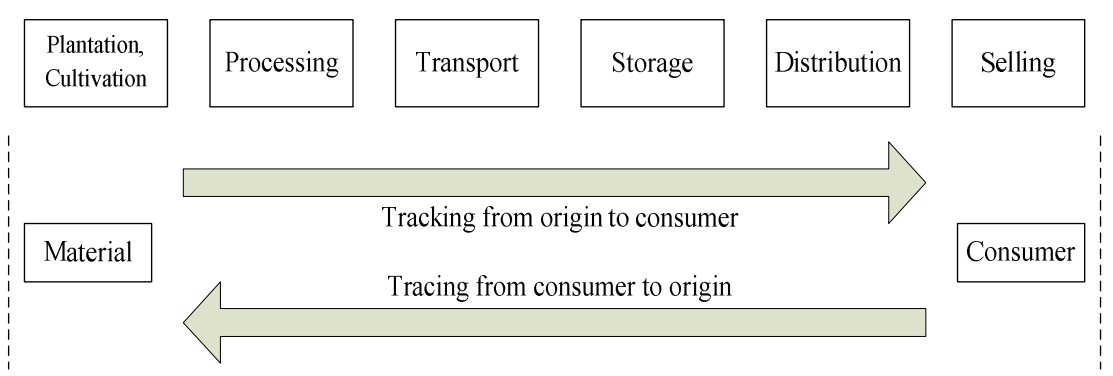

Fig. 2. Process of Tracking and Tracing

\subsection{Task of Tracking and Tracing System of Agricultural Products}

The information system plays an important role in the tracking and tracing logistics system of agricultural products. Such information at least should include, e.g. phase information, geography information and object information. In detail, phase information means the data over the whole life cycle, geography information tells the geographical position of agricultural product's origin and its arrival, object information records all the enterprises engaged in the agricultural product supply chain.

The five tasks of the information system are information input, information transfer, information storage, information process and information output. Gathering and recording the information throughout the agricultural product chain, unifying and standardizing the above information is the primary task of information system. The memory function is also essential since the obtained information would not be lost and distorted. The value of the tracking and tracing logistics information system is eventually embodied for those enterprises or individuals along the whole agricultural product supply chain.

\section{Application of RFID in TTS}

\subsection{Function of RFID}

Radio Frequency Identification (RFID) is commonly known as electronic tag, it is actually a target recognition technology for data interchange in a non-contact duplex communication based on the space coupling of signals such as electromagnetic induction, radio waves and microwaves and so on.

Compared with the traditional ticket, label and tracing card, RFID tags have more advantages. It can not only collect and analyze the data from source to destination but also can keep long distance, quick speed, high data security and excellent capability.

The operation principle of RFID system is shown in Fig. 3: the effective magnetic space is the basic premise of RFID system. The electronic tag with information enters into the magnetic space while the antenna of the reader emits radio signals at a certain frequency. Meanwhile the electronic tag is activated by the power derived from the faradic current, sends messages stored in the chip through the built-in antenna after decoding. The receiving antenna conveys these signals to the reader. The reader decodes 


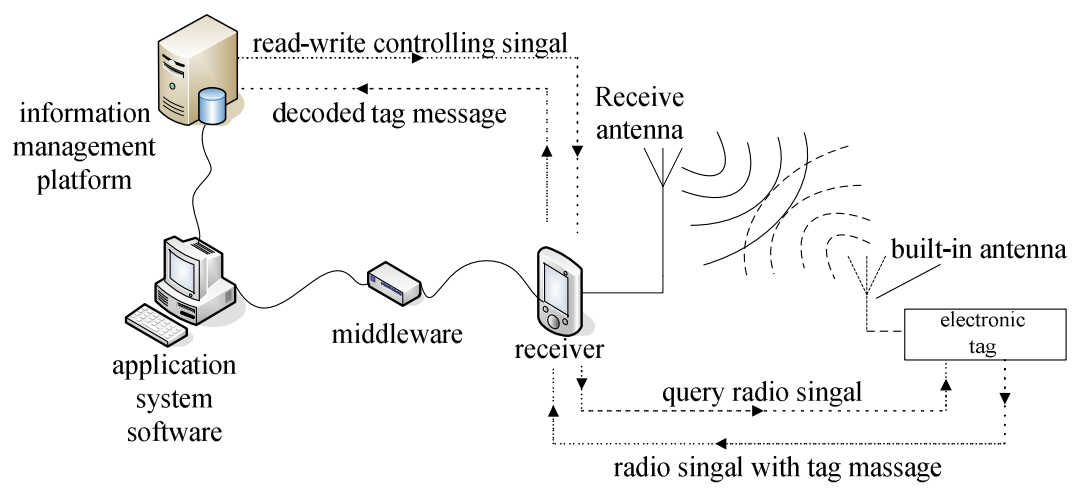

Fig. 3. Operation principle of RFID system

the signals, all the decoded signals are conveyed to the information management platform through the application system software for processing and controlling ${ }^{[8]}$.

\subsection{RFID Applied in Production}

Each RFID tag can be set for each plantation, cultivation, crops and livestock in order to match with the requirements of RFID system. RFID tag records not only the information during plantation and cultivation, such as humidity, light, wind speed, rainfall, but also nutriment or fodder variety and order time. What is more, the different agricultural product and healthy condition can also be added. RFID tags could be placed into collar, card, injection, pill or just on agricultural products' packages ${ }^{[9]}$.

Owing that all the essential information of agricultural product has been stored to the RFID tag, the circulation speed would be faster, the error rate would be lower. In addition, RFID system provides the basic data such as point of sale system, electronic data interchange system and electronic commerce system for processing enterprises, logistics enterprises, sales agencies, and the initial data for the tracking and tracing system of agricultural products.

\subsection{RFID Applied in Processing}

It is convenient for processing enterprises simultaneously add information on the tag, such as enterprises' code, processing date, processing batch, and package weight, etc. used in processing ${ }^{[10]}$. Therefore, the continuity of agricultural product information can be successfully kept along supply chain.

After enriching processing corporations' information, the end consumers could obtain a panoramic view of relevant information even in wholesale market and retail market.

\subsection{RFID Applied in Transportation}

RFID combined with GPS, real-time supervision and tracking service can be available for agricultural product logistics system. For the owners, they can find out the track of 
their goods via the computer network. For the check officers, goods can be examined only through tag so as to speed up the inspection.

Meanwhile, whether temperature-shift will do harm to fresh agricultural product or not could be decided by reading the information stored in RFID tag.

\subsection{RFID Applied in Storage}

It is obvious the inventory cycle time can be shorter because the data stored in RFID tag is very useful for warehousing management, e.g. before agricultural products entering warehouse, the data stored in RFID tag can directly be transmitted to computer. The computer will emit the warehousing instruction to the suitable rack and slots. Furthermore, the correct inventory pattern can be chosen depending on the product specification and requirement.

\subsection{RFID Applied in Distribution}

The logistics information system of agricultural product will generate the picking and slotting task as soon as it receives the customer's order. The operator could pick out the right product immediately according to the information on the RFID tag scanned by hand-reader. Especially some extra information has been enriched during the distribution process in the RFID tag such as distribution vehicle, distribution route, schedule, etc.

\subsection{RFID Applied in Sales}

Not only the vendors but also the consumers can benefit from RFID application in sales. The vendors can supervise the validity of commodities with the help of RFID tag especially for those perishable products. On the other hand, consumers could gain the basic information along the supply chain from the origin to the destination. RFID can help consumers to ensure the agriculture products' safety.

\subsection{RFID Applied in After-Sales}

On account of the quality granted, the commodities often are recalled. For after-sales, the disabled sectors can be found out immediately through RFID tag. Then some relevant measures can be taken by tracking the whole logistics process of agriculture products.

Therefore, the use of RFID in the whole agricultural products logistics system will help to promote the development of seamless exchanging, reading, writing for agricultural products information.

\section{Case Study-RFID Applied in 2008 Olympic Games}

2008 Beijing Olympic Games is a successful event in the world. Although 2008 Beijing Olympic Games was held in the burning summer, the quality of all kinds of foods is safe and convinced. It is reported that RFID application to the food logistics during 
the Olympic Games help to monitor those foods and ensure the food security. There are no less than 3900 species in 65 categories supervised, and all the crucial foods are labeled with RFID, for instance, rice, flour, oil, meat, fruit, vegetable and dairy product. In addition, a professional database is established for the guarantee on safety. Approximately 17 million sets of foods are provided during the whole Olympic Games. Olympic foods distribution center is established and some measures such as closed transport, entire monitor, and special cars are taken exclusively ${ }^{[11]}$. RFID label is added on foods from their cultivation to production and processing, i.e. from cultivated land to dining table. Thank for the RFID application, safe and high quality foods can be provided by the Chinese government during 2008 Beijing Olympic Games.

\section{Conclusions}

Application of RFID will boom in the coming years on account of the advantages of goods identity and logistics tracing. With the costs reducing, RFID will surely bring out a revolution in agricultural products logistics and turn to be a new-born economic growth.

\section{Acknowledgments}

Thanks for the support from national science fund: On Relation Between Mode of Pig Green Supply Chain and Performance around the Poyang Lake (70962002).

\section{References}

1. Yuan, T.: Research on Constructing Retrospecting System of Agricultural Product Supply Chain. In: Master's Dissertation of Southwest Jiaotong University (2007)

2. Tang, D.: The Key Technology Research of the System of Track and Trace in the Supply Chain of Agricultural Logistics of Sichuan Province. In: Master's Dissertation of Sichuan Normal University (2007)

3. Song, J.: The Characteristic of Agricultural Product Logistics and the Related Problems Research. In: Master's Dissertation of College of Economics \& Management Southwest University (2006)

4. Wang, W.: Research on Agriculture Logistics System Evaluation and Optimization. In: Master's Dissertation of Shandong Normal University (2006)

5. Hou, C., Xia, N.: Applied Research on RFID Technology in China's Agricultural Products Quality and Safety Traceability System. Chinese Agricultural Science Bulletin 26(3), 296298 (2010)

6. Zeng, X.: Study on a EPC Code-based Traceability System for Pork Quality and Safety. In: Master's Dissertation of Northwest A \& F University (2008)

7. Moe, T.: Perspectives on Traceability in Food Manufacture. Trends in Food Science and Technology 9 (1998) 
8. Chang, Q.: RFID Application in Vegetable Supply Chain at Home and Abroad. Radio Frequency Identification Technologies and Applications (5), 18-21 (2008)

9. Li, M., Huang, L.: Application Research of RFID in Agriculture. Anhui Agricultural Sciences 35(20), 6333-6334 (2007)

10. Ling, C., Huang, L.: Application of RFID Technology in Safety Control on Agriculture. Anhui Agricultural Sciences 34(8), 1718-1719 (2006)

11. China Society of Logistics, http://www. cflp.org.cn 